\title{
Designing waste management systems to meet circular economy goals: The Italian case
}

Giacomo Di Foggia, Massimo Beccarello

\section{Preprint}

Citation

Di Foggia, G., \& Beccarello, M. (2021). Designing waste management systems to meet circular economy goals: The Italian case. Sustainable Production and Consumption, 26, 1074-1083. https://doi.org/10.1016/j.spc.2021.01.002

\begin{abstract}
Waste management capacity plays a prominent role in complying with circular economy goals, such as reducing municipal waste disposal by landfilling to $10 \%$. We first analyze the imbalance in municipal solid waste management across Italy by estimating the quantities of waste to be treated using technologies different from those currently in use. Subsequently, we estimate the impact that a system compliant with circular economy goals would have on the cost of waste management. Our empirical analyses are based on an econometric method. The results suggest that Italy could reduce the use of landfill by $11.5 \%$, resulting in a $13 \%$ reduction in mechanical-biological treatment. The waste-to-energy capacity would rise by $4.6 \%$ compared to the current situation, while the organic fraction treatment capacity would increase by $8.3 \%$. Besides the positive impact on the environment, the potential annual savings on the cost of waste management could reach $0.07 \%$, or $0.27 \%$ when the phase corresponding to treatment and disposal is considered. We provide insights into the design of more efficient national waste management plans using a novel approach based on best performers.
\end{abstract}




\section{Introduction}

An efficient waste management system is essential for moving toward a more circular economy, which is increasingly seen as an alternative to the make-use-dispose paradigm (Tisserant et al., 2017). Since waste management capacity is a prominent topic within the development of circular economy policy (Lavee and Nardiya, 2013), an industrial policy aimed at promoting different waste management options is the backbone of an efficient waste management system.

The rates at which countries manage municipal solid waste (MSW) using landfill, waste-toenergy plants (WtE), or composting facilities differ considerably at the global level (Kaza et al., 2018). From a techno-environmental point of view, reducing waste is the crucial point. The recycling of materials and the composting of biodegradable waste outperform the WtE option, which, in turn, is preferable to landfill (Gharfalkar et al., 2015). There is evidence of a trend toward convergence in MSW treatment rates (Castillo-Giménez et al., 2019). For example, for recycling and composting, the European average is $46 \%$, while the average waste sent to landfill is $25 \%$ (Di Foggia and Beccarello, 2018). However, according to Directive (EU) 2018/850, by 2035 the amount of MSW landfilled should not exceed 10\%. The above-mentioned points regarding the preference of methods in waste management refer only to MSW.

From an economic standpoint, there is interest in, and increasing concern about, waste management options, with circular economy goals calling for technologically advanced facilities that may increase the cost of waste management (Swart and Groot, 2015). Nevertheless, such facilities are vital in an integrated waste management system (Cobo et al., 2018). In Italy, the concept of integrated waste management emerged from Legislative Decree 152/2006, which updated Italian environmental legislation in line with EU waste directives. Given that many regions are still struggling to achieve self-sufficiency in waste management, we believe that it is important to understand why some regions comply with self-sufficiency principles and others do not. We argue that the differences are due to an imbalance in the country's level of industrialization, which is most strikingly characterized by the critical WtE undercapacity in Sicily and Lazio. The overcapacity of other regions, including Lombardy and Emilia-Romagna, counterbalances the low level of industrialization of the former regions, as noted in the 2019 annual report of the Regulatory Authority for Energy, Networks, and Environment (ARERA, 2019). Due to waste exports, this situation generates negative environmental and economic externalities.

The situation is urgent for three main reasons. First, there is a need to achieve the circular economy goals regarding landfill disposal and the percentage of sorted waste collection. Second, policymakers need information to support them in understanding the nature of the gap and how to address it through appropriate industrial policy. Third, there is a need to understand how tariffs can 
support the development of facilities to ensure optimal capacity at a regional and national level. In this connection, we developed research questions to clarify the following crucial issues: the imbalance between the amount of waste managed using today's mix of different treatment options and the amount foreseen by circular economy goals, and the economic impact on the cost of developing facilities to meet such goals. Therefore, our purpose is twofold. First, we provide a simple approach that can be used as a model to quantify waste management capacity needs to achieve the circular economy goals by limiting the movement of waste according to the legislation in force. Second, we estimate the economic impact of updating the sector's total treatment capacity, including potential savings that may, in turn, be reinvested in the industry for modernization purposes.

Our results have practical implications for policymaking, since we provide insights into setting up a waste capacity path and defining policy-oriented tariffs to promote alternative waste management options (Scharff, 2014; Schreck and Wagner, 2017). Specifically, our results may assist in the development of policies to promote the overall efficiency and cost-effectiveness of the service while meeting the environmental objectives of the circular economy package. It is important to focus policies on the waste sector's capacity by selecting and promoting different technologies according to deficits or overcapacity, their role within the circular economy strategy, and the potential savings that could be invested to modernize the sector. Although we analyze the Italian situation, several insights may also be useful for other countries, since European and global data indicate heterogeneity in the situations of different countries (Kaza et al., 2018). In terms of theoretical implications, this paper's main contribution to the existing literature is our approach to path identification for a waste management system that is circular economy-compliant.

The remainder of the paper is organized as follows. Section 2 provides a review of related research. Section 3 presents the methods used in the paper, the sample, the variables generated for analysis, the statistical analysis, and the simulation approach. Section 4 provides the results of the analyses. Our results are discussed in Section 5 and conclusions drawn in Section 6.

\section{Literature review}

Fast-paced exploitation of natural resources has resulted in their limited availability, while the growing need to safeguard the ecosystem makes it necessary to move toward a circular economy (Di Foggia and Beccarello, 2018; Ghisellini et al., 2014; Kirchherr et al., 2017). In recent years, as sustainability drivers have prompted governments to commit to moving toward a circular economy, the role of waste management facilities has become a theme in the policy debate (Gullì and Zazzi, 2011; Makarichi et al., 2018; Tisserant et al., 2017; Zeller et al., 2019). By the same token, the role 
of waste separation has gained importance; empirical results show, for example, that the separate collection of the recyclable fraction leads to reduced processing costs at intermediate treatment facilities (Chifari et al., 2017). Waste management facilities have gained importance owing to the increasing complexity of the waste management chain, which moves from waste collection to recovery, recycling, and disposal through various methods and technologies. The selection of waste management approach and technology hinges on the local context in terms of investments, ongoing management (Yao and Van Woerden, 2018), and existing facilities. The same is true for the benefits, which reflect first and foremost on the local context.

As such benefits embed environmental, social, and economic spheres (Blagojević and Tufegdžić, 2016; Loures, 2015), a consistent waste management policy will integrate these three dimensions, considering their benefits for future decision making (Allesch and Brunner, 2014). As with other local infrastructure (Agrawal, 2001), development projects for waste management should be sustainable and should have clearly defined long-term goals (Abdallah et al., 2018; MolinosSenante et al., 2010). In this regard, a recent study of the links between waste management system design and economic sustainability has focused on the synergy between internal waste recovery and outside solutions (Tomić and Schneider, 2020).

Despite the implications for growth demonstrated by econometric studies, significant underinvestment persists in the area of waste management (Amann et al., 2016). For example, WtE plants play a prominent role in progressing toward a circular economy, as they prevent landfill and generate energy. A recent study has emphasized that by upgrading $\mathrm{WtE}$ processes and resource, LCA would help in selecting a cost-effective option to improve exergy efficiency (Fujii et al., 2019). Previous studies have discussed the advantages and disadvantages of this treatment technology from an economic perspective, confirming the importance of thermal treatments in an integrated waste management cycle. Indeed, waste incineration has attracted the interest of economists, especially in terms of external costs and benefits and concerns about market failures associated with the provision of thermal treatment of waste (Massarutto, 2015). Given that landfill is still the main option used to treat and dispose of MSW worldwide, some experts agree that the introduction of mechanical-biological treatment (MBT) is to be recommended for developing countries (Trulli et al., 2018). However, such facilities often face significant opposition from local communities and policymakers (Liu et al., 2019).

Similarly, although WtE plants produce fewer negative environmental externalities than landfill, policymakers have often opposed such facilities (Bocken et al., 2014). Broadly speaking, by reducing the amount of waste sent to landfill, it is possible to recycle more material and enable energy recovery. However, this depends on the availability of suitable alternatives. In this context, a 
recurring theme is the so-called not-in-my-backyard effect, when a project is undesirable because it is considered a threat to health or safety or is associated with a deterioration of a geographical area (Malinauskaite et al., 2017). This effect can lead to an inefficient allocation of resources as, regardless of the distributed benefits, the environmental cost is concentrated in the area where the plant is located. When considering MBT, another noteworthy aspect is the relationship between the efficiency of MBT facilities and the quality of the sorted and unsorted waste. Moreover, by implementing MBT before landfill, the environmental impact and waste mass are reduced by up to 30\% (Trulli et al., 2018).

The development and strengthening of waste management facilities within an industrial development path for the waste management sector is necessary for achieving circular economy goals (Beccarello and Di Foggia, 2016; Liu et al., 2019; Malinauskaite et al., 2017). A shortage of waste management facilities generates inefficient brokerage mechanisms, unjustifiably increasing the cost to taxpayers and negatively impacting the economy. These costs can be funded according to different approaches (Alzamora and Barros, 2020).

Policymakers should find an equilibrium between different options to achieve circular economy goals at a sustainable cost (Beccarello and Di Foggia, 2018; Tisserant et al., 2017), especially when the recovery of materials is maximized (Zaman, 2016) in the context of the growing need to incentivize secondary raw material markets (Schreck and Wagner, 2017). These considerations explain the broad agreement on the desirability of policymakers securing resources for the waste industry to ensure adequate waste management capacity. Policymakers have a set of policy tools at their disposal (Roumboutsos et al., 2014) to support the necessary upgrading. Such tools can be categorized as market-based or command and control, where command and control tools can precede and complement market-based instruments (Böcher, 2012). The underlying paradigm of market-based instruments is the achievement of socially efficient use of environmental resources by shifting the cost of negative externalities associated with resource use to users or polluters (Greiner, 2013). Our results will provide policymakers with reliable information about setting up a waste capacity industrialization path, supporting them in developing policies aimed at promoting the overall efficiency and cost-effectiveness of the service while meeting the environmental targets set by the circular economy package.

At the European level, Directive 2008/98/EC and Regulation 2014/955/EU define the strategy for achieving the circular economy goals through the hierarchical principles of waste management: prevention, preparation for reuse, recycling, recovery, and landfill as a last resort. In Italy, the concept of integrated waste management originates from Legislative Decree 152/2006, which also confirms that recovery and disposal plants are to be considered of overriding national interest for 
the country's modernization and development. Significant aspects to take into consideration include the cost-effectiveness of different waste management options, how regulators can recognize efficient costs to design cost-reflective tariffs of waste management, and the identification of empirical data to support the sustainability of environmental and economic policies.

\section{Methods}

Our research methodology stems from the need to merge regional-level potential drivers of efficiency with nationwide economic impacts. By optimal allocation of facilities, we mean the mix of waste management options operating in a region so that the region itself is compliant with circular economy goals. We attempt to answer the following two research questions:

RQ1: Is there a gap between the waste management capacity across the Italian regions and the optimal level?

RQ2: What is the impact on waste management cost of the efficient allocation of waste management capacity?

The sample used in this paper was obtained through probability sampling, that is, stratified random sampling through which a large population can be divided into smaller groups that do not overlap. The stratification took into consideration all Italian municipalities with more than 1,000 inhabitants. This is because waste data in smaller municipalities are collected by groups of municipalities, making it difficult to attribute exact data to each municipality. The analyses are based on data for 4,723 municipalities spread across the country, comprising $84.4 \%$ of the Italy's population and $59.4 \%$ of its municipalities. Note that most of the missing municipalities are small villages. Indeed, while municipalities with less than 3,000 inhabitants represent $57 \%$ of the total $(4,410$ municipalities), they cover only $9.21 \%$ of the population. The data refer to 2018 , the most recent year available.

Economic data were obtained from official statements on waste tax revenues, indicated in the environmental declaration model, which is updated annually by municipalities and other delegated entities, typically in-house companies that manage the waste tax collection service. The computation of costs per ton of waste was based on data published by the Italian Institute for Environmental Protection and Research (ISPRA). Demographic and morphological data were obtained from the Italian National Statistics Institute (ISTAT) databases. We used primary data retrieved from the above-mentioned official open sources. Figure 1 shows that waste management facilities are unevenly dispersed (see Table A1 for additional information). 

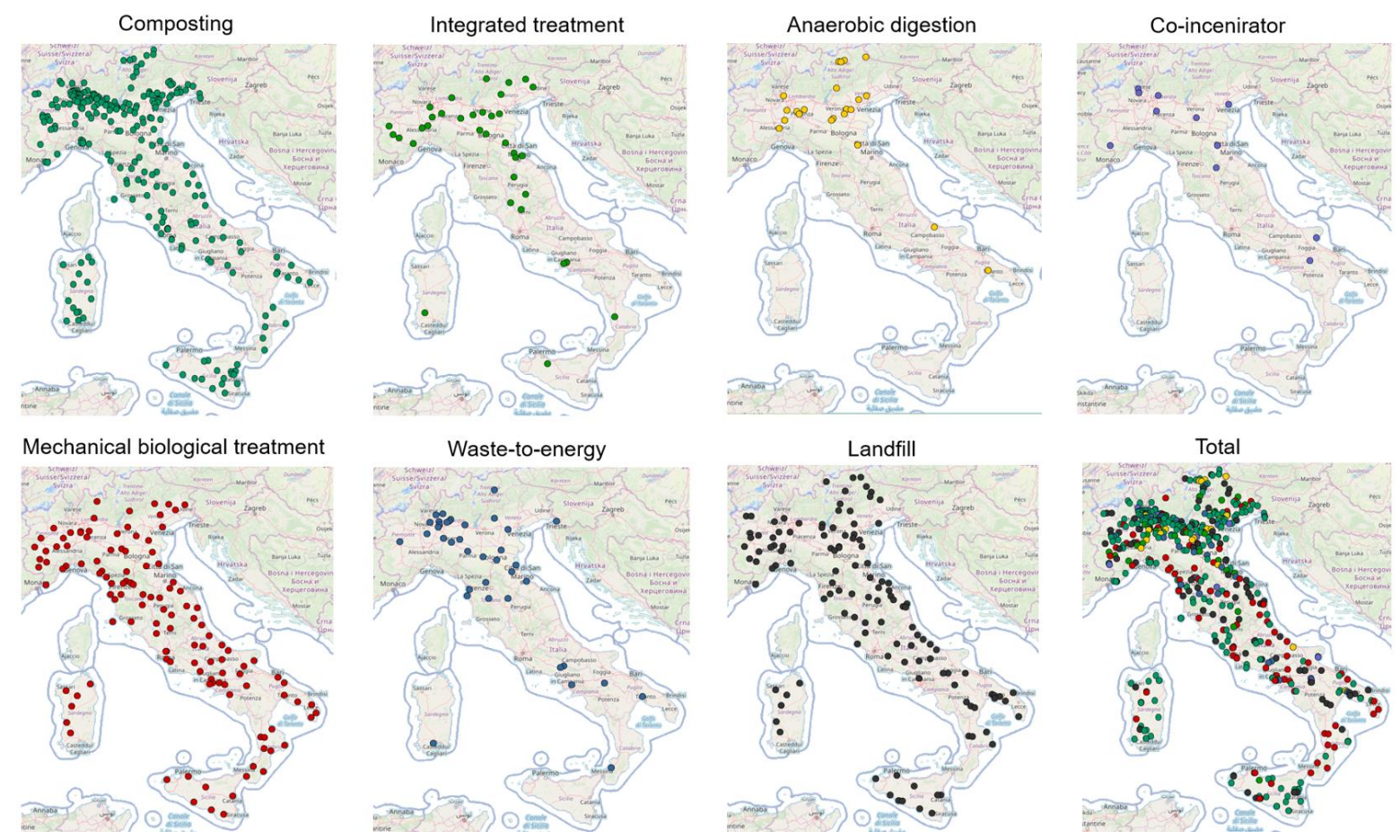

Figure 1. Distribution of waste management facilities across Italy. Source: ISPRA.

Of the approximately 30 million tons of MSW produced in Italy annually, roughly 2 million tons are managed in regions other than where the MSW was generated. The northern regions import $12 \%$ of municipal waste from central and southern regions and send roughly $10 \%$ of total waste managed to landfill. The central regions export around $16 \%$ of their municipal waste, with the share sent to landfill making up 36\%. The southern regions export $7 \%$ of their waste, with $29 \%$ of MSW sent to landfill; see Table A1 for an analytical breakdown of waste facilities by region. Table 1 provides an overview, by region and by population, of the Italian statistics for MSW produced, the share of sorted waste, per capita waste production, and the MSW cost per ton of waste. It reveals consistently significant differences in the information regarding the uneven spread of the facilities across the country, as indicated in Table A1. Recent trends show an increasing production of waste associated with decreasing treatment capacity, generating growth in waste exports and handling outside the production regions.

\begin{tabular}{lcccccc}
\hline Region & $\begin{array}{c}\text { Pop. } \\
(\mathrm{m})\end{array}$ & $\begin{array}{c}\text { Waste produced } \\
(\mathrm{m} \text { ton })\end{array}$ & $\begin{array}{c}\text { Sorted waste } \\
(\%)\end{array}$ & $\begin{array}{c}\text { Waste per capita } \\
(\mathrm{kg})\end{array}$ & $\begin{array}{c}\text { Cost per ton } \\
(€)\end{array}$ & latitude \\
\hline Piedmont & 4.35 & 2.17 & 61.31 & 497.67 & 335.80 & North \\
Aosta Valley & 0.12 & 0.08 & 62.32 & 597.26 & 305.70 & North \\
Lombardy & 10.1 & 4.81 & 70.73 & 478.20 & 291.30 & North \\
Trentino-A A & 1.07 & 0.54 & 72.52 & 505.72 & 267.50 & North \\
Veneto & 4.90 & 2.36 & 73.83 & 481.72 & 381.60 & North \\
Friuli-V G & 1.21 & 0.60 & 66.61 & 494.76 & 257.70 & North \\
Liguria & 1.55 & 0.83 & 49.75 & 536.77 & 432.50 & North
\end{tabular}




\begin{tabular}{lllllll} 
Emilia-R & 4.45 & 2.95 & 67.36 & 660.46 & 265.90 & North \\
Tuscany & 3.73 & 2.28 & 56.17 & 612.43 & 338.80 & Center \\
Umbria & 0.88 & 0.46 & 63.45 & 521.97 & 364.00 & Center \\
Marche & 1.52 & 0.81 & 68.64 & 531.13 & 306.80 & Center \\
Lazio & 5.87 & 3.03 & 47.33 & 514.92 & 419.20 & Center \\
Abruzzo & 1.31 & 0.60 & 59.65 & 460.17 & 354.00 & South \\
Molise & 0.30 & 0.12 & 38.44 & 380.84 & 331.20 & South \\
Campania & 5.80 & 260 & 52.72 & 448.62 & 444.20 & South \\
Apulia & 4.02 & 1.89 & 45.48 & 470.93 & 394.30 & South \\
Basilicata & .056 & 0.19 & 47.39 & 354.30 & 438.60 & South \\
Calabria & 1.94 & 0.79 & 45.27 & 403.37 & 382.10 & South \\
Sicily & 5.00 & 2.29 & 29.55 & 457.86 & 382.50 & South \\
Sardinia & 1.64 & 0.75 & 67.07 & 457.40 & 419.60 & South \\
Italy & 60.3 & 30.19 & 57.22 & 493.33 & 350.10 & \\
\hline
\end{tabular}

Table 1. Key figures on waste production and costs. Source: Own elaboration based on data published by ISPRA.

The information contained in Table 1 corroborates the preliminary considerations on which RQ1 and RQ are based. The percentage of sorted waste differs significantly between different regions, ranging from $29.55 \%$ to $73.95 \%$.

On the basis of previous studies that identified the determinants of the cost of waste management (Deus et al., 2019; Di Foggia and Beccarello, 2020a, 2018; Jacobsen et al., 2013; Massarutto, 2015), the following alphabetically sorted variables were identified: alt, the altitude of the municipalities (logarithm of meters above sea level); cec, circular economy firm total assets per ton of waste; den, population density; geo, an ordinal variable where 1 stands for south, 2 stands for center, and 3 stands for north; lan, the percentage of waste sent to landfill; $m b t$, the percentage of waste sent to MBT; org, the percentage of waste treated using composting, anaerobic digestion, and integrated treatment; sea, denoting a seaside municipality; sor, the percentage of sorted waste; was, the waste produced ( $\mathrm{kg}$ per capita); wmc, the MSW management cost ( $€$ per ton); and wte, the percentage of waste sent to waste-to-energy. See Table A2 for key statistics of the variables presented in Table 2, which shows the correlations between those variables.

\begin{tabular}{|c|c|c|c|c|c|c|c|c|c|c|c|}
\hline & wmc & alt & den & sea & sor & was & $\mathrm{mtb}$ & lan & wte & org & cec \\
\hline wmc & 1 & & & & & & & & & & \\
\hline alt & $.060 * *$ & 1 & & & & & & & & & \\
\hline den & $-.164 * *$ & $-.367 * *$ & 1 & & & & & & & & \\
\hline sea & $.231 * *$ & $-.358 * *$ & $.108 * *$ & 1 & & & & & & & \\
\hline sor & $-.253 * *$ & $-.171 * *$ & $.218^{* *}$ & $-.223 * *$ & 1 & & & & & & \\
\hline was & $-.243 * *$ & $-.258 * *$ & $.080 * *$ & $.254 * *$ & $-.086^{* *}$ & 1 & & & & & \\
\hline $\mathrm{mtb}$ & $.530 * *$ & $.092 * *$ & $-.143^{* *}$ & $.269 * *$ & $-.524 * *$ & $-.185^{* *}$ & 1 & & & & \\
\hline lan & $.305^{* *}$ & $.164 * *$ & $-.287 * *$ & $.242 * *$ & $-.468 * *$ & $-.144 * *$ & $.658 * *$ & 1 & & & \\
\hline
\end{tabular}




\begin{tabular}{llllllllllll} 
wte & $-.340 * *$ & 0.028 & $.252 * *$ & $-.240 * *$ & $.253 * *$ & $.107 * *$ & $-.490 * *$ & $-.559 * *$ & 1 & \\
org & $-.475 * *$ & $-.251 * *$ & $.085 * *$ & $-.199 * *$ & $.428 * *$ & $.070 * *$ & $-.521 * *$ & $-.307 * *$ & $.255 * *$ & 1 \\
cec & $-.542 * *$ & $-.084 * *$ & $.063 * *$ & $-.240 * *$ & $.309 * *$ & $.347 * *$ & $-.693 * *$ & $-.457 * *$ & $.423 * *$ & $.449 * *$ & 1 \\
\hline
\end{tabular}

Table 2. Correlations between variables used in the models. Source: Own elaboration.

Note: ** Correlation is significant at the 0.01 level (two tails).

Some empirical evidence can be drawn from Table 2, especially on the relationship between the three types of facilities that are the focus of this paper. First, a complementarity between WtE and landfill (-0.559) and between WtE and MBT (-0.490) emerges, reflecting the fact that the two technologies are complementary and are positioned at the base of the waste hierarchy. This complements the graphical evidence in Figure 1 showing that $\mathrm{WtE}$ plants are concentrated in areas where there are few landfills, and vice versa. The second correlation shows that as the percentage of waste treated in $\mathrm{WtE}$ plants increases, the percentage of waste treated using MBT decreases; the meaning of this is not apparent while the relationship between landfill and MBT is positive (0.657).

Econometric analysis can be used to estimate the impact of different facilities on waste management costs and to simulate waste management capacity deficits at the regional level. Here, we use regression analysis, as it is acknowledged as helpful to waste management planners and policymakers in understanding how to improve existing waste management systems, how to define regulations, and how to evaluate current waste management strategies (Al-Khatib et al., 2016). We assume that there is room for major improvements resulting from the appropriate location of waste management facilities. We also predict that although treatment facilities generally have higher operating costs than landfill, the optimal allocation of waste management facilities will generate savings that can be invested in technological innovation.

Several studies have investigated environmental, economic, and social waste management indicators (Deus et al., 2019) in the economics of MSW management, including the variables that impact waste processing profitability (Rajendran et al., 2018). In addition to typical cost drivers that influence waste management costs, we focus on the implications of different plant types on such costs. Based on previous evidence, the hypothesis is that the availability of facilities other than landfill reduces negative environmental externalities and may reduce the cost of waste management.

The research framework consists of three variable clusters. The first cluster captures territorial features, namely the density den, the altitude alt, and seaside location sea. In addition to geographical features, the second cluster contains variables that capture the service's characteristics in terms of the share of sorted waste, sor, and waste produced per capita, was. The third cluster contains variables related to waste management facilities. Two additional variables were used to run the analysis: geo and cec. 
Waste management cost (total cost, disposal cost, or treatment cost) is a function of the independent variables as in Eq. (1):

$$
\text { cost }=f\left\{\begin{array}{c}
\text { territorial features: den, alt, sea } \\
\text { service: sor, was } \\
\text { facilities: } m b t, \text { lan, wte, org }
\end{array}\right.
$$

To determine the influence of treatment and disposal options on waste management costs, it is appropriate to perform an econometric analysis using a multiple regression model as in Eq. (2). Multiple regression can predict the value of a variable based on the value of two or more other variables (Wooldridge, 2020), using the ordinary least squares estimators widely used to estimate the parameter of linear regression models. In Eq. (2), $Y$ is the dependent variable:

$$
Y=\propto+\beta_{1} X_{1}+\beta_{2} X_{2}+\beta_{3} X_{3}+\beta_{n} X_{n}+\varepsilon
$$

The multiple regression models are formalized in Eq. (3), while Eq. (4) and Eq. (5) represent a special case. Eq. (4) models only the treatment and disposal cost and thus excludes the variable org. In contrast, Eq. (5) includes the recovery costs and, consequently, excludes the variables lan and wte:

$$
w m c=\propto+\beta_{1} \text { alt }+\beta_{2} \text { den }+\beta_{3} \text { sor }+\beta_{4} w a s+\beta_{5} m b t+\beta_{6} \text { lan }+\beta_{7} w t e+\beta_{8} \text { org }+\beta_{9} c e c+\varepsilon
$$

In the same way, Eq. (4) formalizes the model related to disposal costs:

$$
\text { dis }=\propto+\beta_{1} \text { alt }+\beta_{2} \text { den }+\beta_{3} \text { sor }+\beta_{4} w a s+\beta_{5} m b t+\beta_{6} \text { lan }+\beta_{7} w t e+\beta_{8} c e c+\varepsilon
$$

Eq. (5) formalizes the model related to recovery costs:

$$
\text { rec }=\propto+\beta_{1} \text { alt }+\beta_{2} \text { den }+\beta_{3} \text { sor }+\beta_{4} \text { was }+\beta_{5} m b t+\beta_{6} \text { org }+\beta_{7} c e c+\varepsilon
$$

From the results of the model formalized in Eq. (3), it is possible to develop a simulation and quantify the technical and economic variables bearing in mind the targets: minimization of landfill and maximization of separate collection. To estimate potential imbalances in waste management capacity, an analysis was carried out using reference data from the best-performing regions in the two target areas: $65 \%$ separate collection and $10 \%$ of municipal waste sent to landfill, see Fig. 2. In what follows, this is referred to as the frontier. 
Best performers: minimization of landfilling and maximization of the percentage of separate collection

Benchmark: average value of the share of waste sent to each plant typology

Distance between the benchmark and each region

Waste treatment gap to convergence: regional level

Cost of convergence: regional level

Total waste treatment gap to convergence

Total cost of convergence

Figure 2. Summary of the simulation approach. Source: Own elaboration.

The frontier values were calculated using data from the best-performing regions as in Table 3 . For comparison purposes, we developed three frontier scenarios according to the number of regions included. Then, the percentages of waste treated by each type of plant located in the bestperforming regions were averaged. Given that such regions are relatively close to, or have already achieved, the goals, it is fair to suppose that the more backward regions may aim to converge toward the best-performing regions

\begin{tabular}{lcccc}
\hline Frontier & Org & WtE & Landfill & MBT \\
\hline 3 & 38.01 & 25.12 & 07.24 & 21.41 \\
4 & 33.81 & 23.03 & 12.13 & 21.92 \\
5 & 30.32 & 25.02 & 11.03 & 21.43 \\
Avg. & 34.04 & 24.39 & 10.13 & 21.58 \\
\hline
\end{tabular}

Table 3. Average share of waste treated by facilities in best-performing regions. Source: Own elaboration.

\section{Results}

We aimed to understand the imbalance between the amount of waste treated by the current mix of facilities in the Italian regions and the amount that could be treated if the optimal allocation of facilities to comply with circular economy goals were achieved. Consequently, we wanted to estimate the economic impact of an industrial policy aimed at steering sector industrialization to meet those goals. Therefore, we designed a two-step analysis process. Tables 4 and 5 present the 
results of the first step. The outputs of the econometric analysis in Table 4 provide particularly interesting insights. In column (1), the model refers to the total cost of waste management, and the variables related to facilities are noteworthy. Whereas landfill $(-0.664 * * *)$ and $\mathrm{WtE}(-0.436 * * *)$ reduce the cost of waste management, MBT increases the cost to $1.215^{* * *}$. This is a significant item of information given that, as anticipated, the regions with severe imbalances make greater use of these technologies to process waste that is subsequently exported, with the associated negative economic and environmental externalities. Furthermore, it can be observed that the cost of services tends to decrease as the use of integrated treatment, anaerobic digestion, and composting facilities increases.

\begin{tabular}{|c|c|c|c|}
\hline Variables & $\begin{array}{l}\text { WM cost } \\
\text { (1) }\end{array}$ & $\begin{array}{l}\text { Disposal } \\
\text { (2) }\end{array}$ & $\begin{array}{l}\text { Recovery } \\
\text { (3) }\end{array}$ \\
\hline alt & $\begin{array}{l}-4.902 * * * \\
(1.057)\end{array}$ & $\begin{array}{l}-3.355^{* * * *} \\
(0.867)\end{array}$ & $\begin{array}{l}-1.258 \\
(1.402)\end{array}$ \\
\hline den & $\begin{array}{l}-11.73 * * * \\
(1.007)\end{array}$ & $\begin{array}{l}-9.339 * * * \\
(0.867)\end{array}$ & $\begin{array}{l}-0.503 \\
(1.296)\end{array}$ \\
\hline sea & $\begin{array}{l}41.82 * * * \\
(4.895)\end{array}$ & $\begin{array}{l}11.32 * * * \\
(4.203)\end{array}$ & $\begin{array}{l}-4.613 \\
(6.805)\end{array}$ \\
\hline sor & $\begin{array}{l}0.236 * * * \\
(0.0773)\end{array}$ & $\begin{array}{l}0.776 * * * \\
(0.0657)\end{array}$ & $\begin{array}{l}-0.512 * * * \\
(0.108)\end{array}$ \\
\hline was & $\begin{array}{l}-0.114 * * * \\
(0.0103)\end{array}$ & $\begin{array}{l}-0.0318 * * * \\
(0.00894)\end{array}$ & $\begin{array}{l}-0.0504 * * * \\
(0.0142)\end{array}$ \\
\hline $\mathrm{mbt}$ & $\begin{array}{l}1.215 * * * \\
(0.0959)\end{array}$ & $\begin{array}{l}0.582 * * * \\
(0.0804)\end{array}$ & $\begin{array}{l}0.427 * * * \\
(0.124)\end{array}$ \\
\hline lan & $\begin{array}{l}-0.664 * * * \\
(0.0824)\end{array}$ & $\begin{array}{l}-0.550 * * * \\
(0.0712)\end{array}$ & \\
\hline wte & $\begin{array}{l}-0.436 * * * \\
(0.0973)\end{array}$ & $\begin{array}{l}-0.193 * * \\
(0.0851)\end{array}$ & \\
\hline org & $\begin{array}{l}-1.631 * * * \\
(0.0893)\end{array}$ & & $\begin{array}{l}-0.351 * * * \\
(0.122)\end{array}$ \\
\hline cec & $\begin{array}{l}-0.215^{* * * *} \\
(0.0165)\end{array}$ & $\begin{array}{l}-0.0819 * * * \\
(0.0141)\end{array}$ & $\begin{array}{l}-0.0333 \\
(0.0223)\end{array}$ \\
\hline Constant & $\begin{array}{l}526.3 * * * \\
(13.74)\end{array}$ & $\begin{array}{l}201.6 * * * \\
(11.47)\end{array}$ & $\begin{array}{l}126.0 * * * \\
(19.18)\end{array}$ \\
\hline $\begin{array}{l}\text { Observations } \\
\text { R-squared }\end{array}$ & $\begin{array}{l}4,702 \\
0.426 \\
\end{array}$ & $\begin{array}{l}4,534 \\
0.098 \\
\end{array}$ & $\begin{array}{l}3,940 \\
0.050 \\
\end{array}$ \\
\hline
\end{tabular}

Table 4. Econometric analysis. Source: Own elaboration.

Note: Standard error in parentheses. $* * * p<0.01$, ** $p<0.05, * p<0.1$. (1) total cost of waste management service, (2) treatment and disposal, (3) treatment and recovery. See Table A3 for additional information on robust standard errors and confidence intervals. 
In addition to the considerations in Table 4 on the impact of treatment facility costs, further valuable information can be found. Altitude is associated with lower costs $(-4.902 * * *)$, probably because the inclusion of fewer productive activities leads to greater homogeneity of waste. Organizing separate collection involves an increase in costs $\left(0.236^{* * *}\right)$. There are fewer constraints on the organization of the service compared to urbanized areas. Greater population density implies a cost reduction $(-11.73 * * *)$, as does the waste produced per capita $(-0.114 * * *)$. This is partly because the load factor of the vehicles used to run the service is optimized. It is noteworthy that coastal municipalities tend to have higher costs $(41.82 * * *)$. From the regression analysis, it was possible to derive the factors shown in Table 5, which represent the percentage change of cost as a $1 \%$ increase in the use of the facility types, implying an elasticity of cost.

\begin{tabular}{lc}
\hline Facility & Percentage change \\
\hline WtE & $-0.14 \%$ \\
Lan & $-0.21 \%$ \\
MBT & $0.38 \%$ \\
Org & $-0.52 \%$ \\
\hline
\end{tabular}

Table 5. Percentage change of cost on the percentage of waste treated in different facilities. Source: Own elaboration.

Given that the average cost per ton of waste is $€ 316.51$, Table 5 shows the percentage changes in waste management costs for waste treated or disposed of in different facilities. The values in the table were obtained by applying to the average cost of the service the impact on such costs according to the percentage of use of the various waste management options, as shown in the parameters of Table 4 . When considering the cost per ton of waste, a $1 \%$ increase in waste treated by WtE plants corresponds to a $0.14 \%$ decrease in cost. A $1 \%$ increase in waste sent to landfill corresponds to a $-0.21 \%$ decrease in cost. An increase of $1 \%$ in waste treated at facilities for organic waste corresponds to a $-0.52 \%$ decrease in cost. Finally, a $1 \%$ increase in waste treated in MBT plants leads to a $0.38 \%$ increase in cost.

Based in Table 3 data, Table 6 contains a simulation of quantities and economic impact of an optimized WM system according to our analyses. Clear indications emerge from the simulation scenarios in Table 6, confirming that an imbalance arises from a suboptimal allocation of waste to treatment facilities. This imbalance differs according to the frontier that is taken as a reference. For simplicity, average values are considered in the discussion and conclusion of this paper. Tables 6 is divided into 6 section depending on type of information and unite of measure as reported in the section headers. 


\begin{tabular}{|c|c|c|c|c|c|}
\hline Frontier & Org & WtE & Landfill & MBT & Total \\
\hline \multicolumn{6}{|c|}{ Quantities: waste treatment balance: tons } \\
\hline & Org & WtE & landfill & MBT & \\
\hline 3 & 3.68 & 1.60 & -4.33 & -3.95 & \\
\hline 4 & 2.41 & 0.98 & -2.83 & -3.82 & \\
\hline 5 & 1.37 & 1.58 & -3.19 & -3.94 & \\
\hline avg. & 2.23 & 1.24 & -3.74 & -3.53 & \\
\hline \multicolumn{6}{|c|}{ Quantities: waste management balance (\%) } \\
\hline & Org & WtE & landfill & MBT & \\
\hline 3 & $12.20 \%$ & $5.30 \%$ & $-14.40 \%$ & $-13.10 \%$ & \\
\hline 4 & $8.00 \%$ & $3.30 \%$ & $-9.40 \%$ & $-12.70 \%$ & \\
\hline 5 & $4.60 \%$ & $5.30 \%$ & $-10.60 \%$ & $-13.10 \%$ & \\
\hline avg. & $8.30 \%$ & $4.60 \%$ & $-11.50 \%$ & $-13.00 \%$ & \\
\hline \multicolumn{6}{|c|}{ Potential savings (€m) } \\
\hline & Org & $\mathrm{WtE}$ & Landfill & MBT & total \\
\hline 3 & -6.00 & -0.70 & 2.88 & -4.80 & -8.62 \\
\hline 4 & -3.93 & -0.43 & 1.88 & -4.64 & -7.12 \\
\hline 5 & -2.24 & -0.69 & 2.12 & -4.79 & -5.61 \\
\hline avg. & -4.06 & -0.61 & 2.29 & -4.74 & -7.11 \\
\hline \multicolumn{6}{|c|}{ Potential saving: full cost of WM (i.e., waste tax) (\%) } \\
\hline & Org & WtE & Landfill & MBT & total \\
\hline 3 & $-0.06 \%$ & $-0.01 \%$ & $0.03 \%$ & $-0.05 \%$ & $-0.09 \%$ \\
\hline 4 & $-0.04 \%$ & $0.00 \%$ & $0.02 \%$ & $-0.05 \%$ & $-0.07 \%$ \\
\hline 5 & $-0.02 \%$ & $-0.01 \%$ & $0.02 \%$ & $-0.05 \%$ & $-0.06 \%$ \\
\hline avg. & $-0.04 \%$ & $-0.01 \%$ & $0.02 \%$ & $-0.05 \%$ & $-0.07 \%$ \\
\hline \multicolumn{6}{|c|}{ Potential saving: WM service $(\%)$} \\
\hline & Org & WtE & Landfill & MBT & total \\
\hline 3 & $-0.08 \%$ & $-0.01 \%$ & $0.04 \%$ & $-0.06 \%$ & $-0.12 \%$ \\
\hline 4 & $-0.05 \%$ & $-0.01 \%$ & $0.03 \%$ & $-0.06 \%$ & $-0.10 \%$ \\
\hline 5 & $-0.03 \%$ & $-0.01 \%$ & $0.03 \%$ & $-0.06 \%$ & $-0.08 \%$ \\
\hline avg. & $-0.05 \%$ & $-0.01 \%$ & $0.03 \%$ & $-0.06 \%$ & $-0.10 \%$ \\
\hline \multicolumn{6}{|c|}{ Potential saving: treatment phase cost $(\%)$} \\
\hline & Org & $\mathrm{WtE}$ & Landfill & MBT & total \\
\hline 3 & $-0.23 \%$ & $-0.03 \%$ & $0.11 \%$ & $-0.18 \%$ & $-0.33 \%$ \\
\hline 4 & $-0.15 \%$ & $-0.02 \%$ & $0.07 \%$ & $-0.18 \%$ & $-0.27 \%$ \\
\hline 5 & $-0.09 \%$ & $-0.03 \%$ & $0.08 \%$ & $-0.18 \%$ & $-0.22 \%$ \\
\hline avg. & $-0.16 \%$ & $-0.02 \%$ & $0.09 \%$ & $-0.18 \%$ & $-0.27 \%$ \\
\hline
\end{tabular}

Table 6. Simulation of quantities and economic impact of an optimized WM system. Source: Own elaboration.

Table 6 shows that the use of landfill should be reduced by $11.5 \%$ or 3.7 million tons, which would result in a reduction of $13 \%$ (3.53 million tons) in waste sent to MBT. Ceteris paribus, this reduction would be compensated by an increase of $4.6 \%$, corresponding to 1.2 million tons of $\mathrm{WtE}$ capacity, and an increase of $8.3 \%$ in the organic fraction plants corresponding to 2.23 million tons. 
From an economic standpoint, it is also possible to infer from Table 6 that the three scenarios correspond to savings ranging from $€ 5.61$ million to $€ 8.62$ million per year, an average of $€ 7.11 \mathrm{~m}$. The potential saving is better contextualized in terms of the $€ 10.04$ billion total cost of waste management services; the annual saving is $0.07 \%$. Considering the phase corresponding to treatment and disposal, the annual saving would amount to $0.27 \%$.

\section{Discussion}

The results make it possible to formulate several considerations that are useful in understanding how to design policies to promote the overall efficiency and cost-effectiveness of waste management systems while meeting environmental objectives. It is also essential to focus policies on the sector's infrastructural capacity by selecting and promoting different waste management facilities according to the current situation.

We have used a simulation based on empirical data to answer the proposed RQs. First, in response to RQ1, there is an imbalance in plant equipment in the Italian regions, and we calculate this imbalance for each plant type. Second, in response to RQ2, we estimate the economic impact of convergence toward the frontier of efficiency. Specifically, the viability of the investments needed to implement an industrial policy that involves the reprogramming of waste management facilities could be facilitated by the potential savings achieved through optimal allocation of plants. These answers to the research questions are highly significant because we provide useful evidence for policymakers, who can use our results to support industrial and environmental policy to maximize the efficiency of the waste management system and its compliance with circular economy goals.

In light of the results of our econometric analysis, it is appropriate to consider MBT, given its impact on the cost of waste management services. A $1 \%$ increase in waste treated by MBT facilities increases the cost of the waste management service by $€ 1.215$ per ton of waste. Figure 3 presents an overview of the waste management chain, showing the cost of the phase concerning the total cost of waste management services and the destination of the waste processed in MBT facilities. (See Table A1 for a breakdown of the data by region.) 


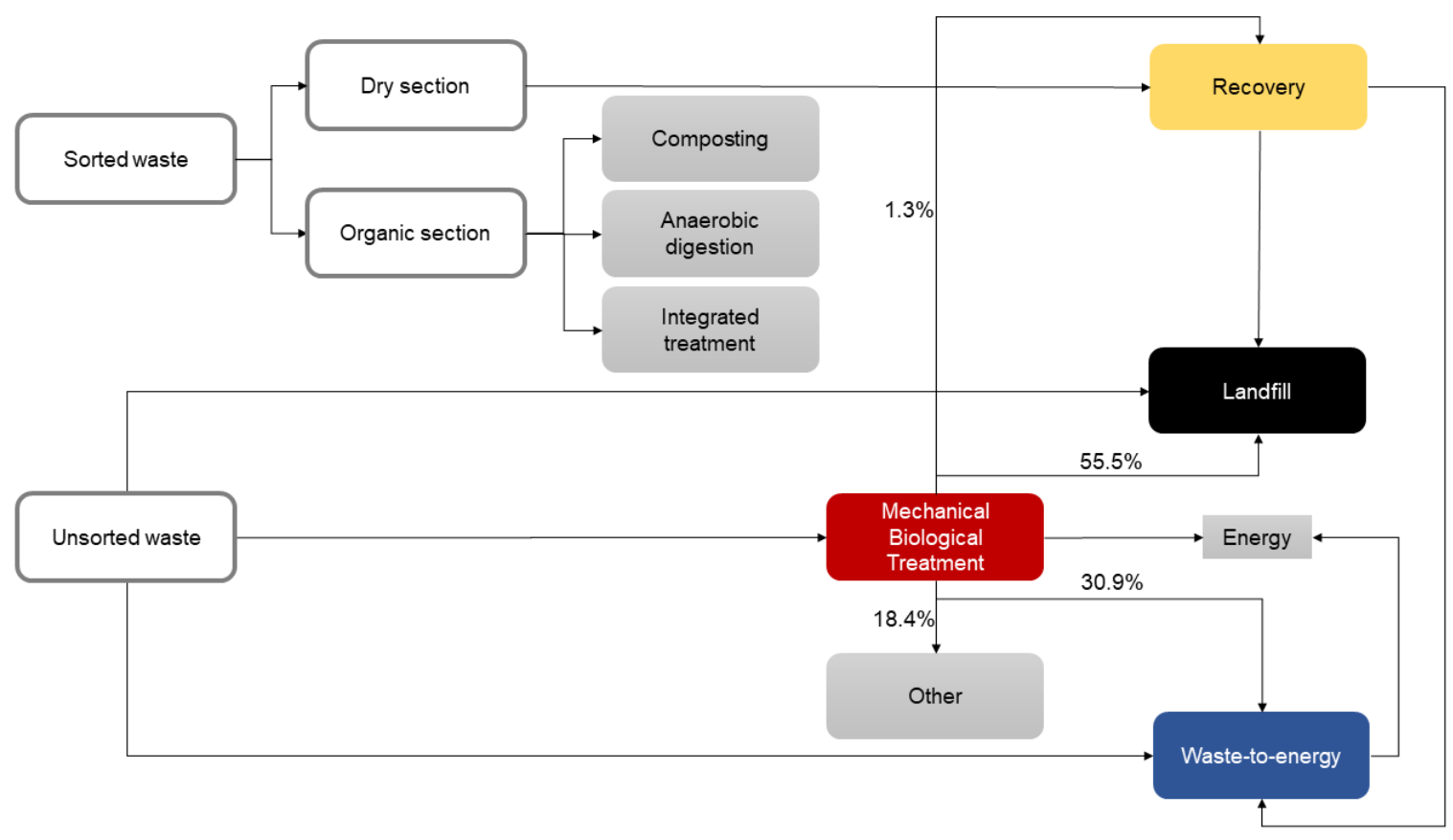

Figure 3. The waste management chain in Italy. Source: Own elaboration based on data retrieved from ISPRA.

Note: "Other" includes further treatment, sewage treatment plant, storage of materials, and landfillcovering soil.

According to the information in Figure 3, 55.5\% of the waste treated in MBT facilities is sent to landfill, $30.9 \%$ goes to $\mathrm{WtE}$ plants, and $18.4 \%$ reaches other facilities; just $1.3 \%$ is sent to recovery and recycling facilities (see Figure A1 for further details). Although some limitations relate to the fact that this paper is based on MSW only, our results can be trusted, given the size of the sample, the sources of the data, the partial corroboration of previous studies, and the importance of datadriven evidence to the policy debate. Furthermore, the Breusch-Pagan test for heteroscedasticity with Ho: Constant variance provided the following values: $\operatorname{chi}^{2}(1)=282.68$, prob $>\operatorname{chi}^{2}=0.000$. We can therefore reject the null hypothesis and conclude that heteroscedasticity is present in the data.

Thus, our results provide policymakers with information for setting up a waste capacity industrialization path, and regulators with support regarding how and to what extent they should define tariffs for the use of facilities (Scharff, 2014; Schreck and Wagner, 2017). Specifically, and consistently with previous studies, these results can support policymakers to design policies that promote the overall efficiency and cost-effectiveness of the service while meeting the environmental objectives set by the circular economy package (Di Foggia and Beccarello, 2020a). It is also important to focus policies on the waste sector's infrastructural capacity by selecting and promoting different waste management facilities. However, for this to happen, a national strategy 
should be in place and, if necessary, should take precedence over local plans. This would not be a straightforward process, given the complexities of securing permits to build new facilities and the management of consensus by political decision-makers.

At present, the use of MBT plants represents a step toward exporting waste produced in one region to other regions by changing the classification of the waste processed in these facilities from municipal waste to special waste. Therefore, to maximize the social benefits that result from the combined environmental and economic benefits, policymakers should design policies aimed at rationalizing the flow of waste toward the most suitable facilities, as well as policies aimed at increasing the sorted share of waste through gain-sharing mechanisms that encourage people to be part of a virtuous system (Di Foggia and Beccarello, 2020b). From this perspective, it can be argued that the main inefficiency lies in the governance model and in the powers attributed to central government and the regions at the planning stage. The law provides that each region is selfsufficient in waste management, but this constitutes an important barrier to the development of new plants. Moreover, in some regions, there is both deep-rooted political opposition to and strong public opinion against $\mathrm{WtE}$ in particular.

\section{Conclusion}

The need to understand how and to what extent waste management systems are to be upgraded to comply with circular economy directives such as Directive EU 2018/850, according to which MSW landfill should be reduced to $10 \%$ of MSW, justifies our research questions. Using empirical data at the local level, we have highlighted an imbalance in waste management capacity in Italy. We have estimated the quantities of waste that will have to be treated using technologies different from those currently used, along with the impact that a system compliant with circular economy goals would have on the cost of services.

Our results confirm that landfill use should be reduced by $11.5 \%$, which would result in a $13 \%$ reduction in the use of MBT plants. However, it will be necessary to increase the treatment capacity in WtE plants by $4.6 \%$ compared to the current situation. Furthermore, an $8.3 \%$ increase in organic fraction facilities is essential.

From an economic point of view, our estimates suggest potential annual savings of up to $€ 8.62$ million per year. These potential savings can be better contextualized by comparing them to the total cost of the waste management service, which amounts to $€ 10.04$ billion; the annual saving would be $0.07 \%$. However, when considering the phase corresponding only to treatment and disposal, and excluding the collection and transport phase and the general costs not directly attributable to the treatment and disposal of waste, the annual savings would come to $0.27 \%$. 
Our results are particularly important for the assistance they provide to policymakers in defining an industrial policy to create the technological assumptions underlying a country's ability to achieve circular economy goals. Future research should investigate the use of a comparative perspective on the cost-effectiveness of the different facilities and the regulatory role, examining how the tariff for sending waste to facilities can have a signaling function. It would also be useful to apply a cross-country approach to the comparison of waste management capacity mix. Likewise, the present findings should be complemented by the identification of empirical data that support policies for environmental and economic sustainability.

\section{References}

Abdallah, M., Shanableh, A., Shabib, A., Adghim, M., 2018. Financial feasibility of waste to energy strategies in the United Arab Emirates. Waste Manag. 82, 207-219. https://doi.org/10.1016/j.wasman.2018.10.029

Agrawal, A., 2001. Common property institutions and sustainable governance of resources. World Dev. 29, 1649-1672. https://doi.org/10.1016/S0305-750X(01)00063-8

Al-Khatib, I.A., Abu Fkhidah, I., Khatib, J.I., Kontogianni, S., 2016. Implementation of a multivariable regression analysis in the assessment of the generation rate and composition of hospital solid waste for the design of a sustainable management system in developing countries. Waste Manag. Res. 34, 225-234. https://doi.org/10.1177/0734242X15622813

Allesch, A., Brunner, P.H., 2014. Assessment methods for solid waste management: A literature review. Waste Manag. Res. 32, 461-473. https://doi.org/10.1177/0734242X14535653

Alzamora, B.R., Barros, R.T. de V, 2020. Review of municipal waste management charging methods in different countries. Waste Manag. 115, 47-55. https://doi.org/https://doi.org/10.1016/j.wasman.2020.07.020

Amann, E., Baer, W., Trebat, T., Lora, J.V., 2016. Infrastructure and Its Role in Brazil's Development Process. Q. Rev. Econ. Financ. 62, 66-73. https://doi.org/10.1016/j.qref.2016.07.007

ARERA, 2019. Annual report. Rome.

Beccarello, M., Di Foggia, G., 2018. Moving towards a circular economy: economic impacts of higher material recycling targets. Mater. Today Proc. 5, 531-543. https://doi.org/10.1016/j.matpr.2017.11.115

Beccarello, M., Di Foggia, G., 2016. Economic Analysis of EU Strengthened Packaging Waste 
Recycling Targets. J. Adv. Res. Law Econ. 7, 1930-1941.

https://doi.org/10.14505/jarle.v7.8(22).02

Blagojević, M.R., Tufegdžić, A., 2016. The new technology era requirements and sustainable approach to industrial heritage renewal. Energy Build. 115, 148-153. https://doi.org/10.1016/j.enbuild.2015.07.062

Böcher, M., 2012. A theoretical framework for explaining the choice of instruments in environmental policy. For. Policy Econ. 16, 14-22. https://doi.org/10.1016/j.forpol.2011.03.012

Bocken, N.M.P., Short, S.W., Rana, P., Evans, S., 2014. A literature and practice review to develop sustainable business model archetypes. J. Clean. Prod. 65, 42-56. https://doi.org/10.1016/j.jclepro.2013.11.039

Castillo-Giménez, J., Montañés, A., Picazo-Tadeo, A.J., 2019. Performance in the treatment of municipal waste: Are European Union member states so different? Sci. Total Environ. 687, 1305-1314. https://doi.org/10.1016/J.SCITOTENV.2019.06.016

Chifari, R., Lo Piano, S., Matsumoto, S., Tasaki, T., 2017. Does recyclable separation reduce the cost of municipal waste management in Japan? Waste Manag. 60, 32-41. https://doi.org/10.1016/J.WASMAN.2017.01.015

Cobo, S., Dominguez-Ramos, A., Irabien, A., 2018. From linear to circular integrated waste management systems: A review of methodological approaches. Resour. Conserv. Recycl. 135, 279-295. https://doi.org/10.1016/J.RESCONREC.2017.08.003

Deus, R.M., Bezerra, B.S., Battistelle, R.A.G., 2019. Solid waste indicators and their implications for management practice. Int. J. Environ. Sci. Technol. 16, 1129-1144. https://doi.org/10.1007/s13762-018-2163-3

Di Foggia, G., Beccarello, M., 2020a. Drivers of municipal solid waste management cost based on cost models inherent to sorted and unsorted waste. Waste Manag. 114, 202-214. https://doi.org/10.1016/j.wasman.2020.07.012

Di Foggia, G., Beccarello, M., 2020b. The impact of a gain-sharing cost-reflective tariff on waste management cost under incentive regulation : The Italian case. J. Environ. Manage. 265, 110526. https://doi.org/10.1016/j.jenvman.2020.110526

Di Foggia, G., Beccarello, M., 2018. Improving efficiency in the MSW collection and disposal service combining price cap and yardstick regulation: The Italian case. Waste Manag. 79, 223231. https://doi.org/10.1016/j.wasman.2018.07.040 
Fujii, M., Dou, Y., Sun, L., Ohnishi, S., Maki, S., Dong, H., Dong, L., Chandran, R., 2019.

Contribution to a low-carbon society from improving exergy of waste-to-energy system by upgrading utilization of waste. Resour. Conserv. Recycl. 149, 586-594.

https://doi.org/https://doi.org/10.1016/j.resconrec.2019.06.038

Gharfalkar, M., Court, R., Campbell, C., Ali, Z., Hillier, G., 2015. Analysis of waste hierarchy in the European waste directive 2008/98/EC. Waste Manag. 39, 305-313. https://doi.org/10.1016/J.WASMAN.2015.02.007

Ghisellini, P., Cialani, C., Ulgiati, S., 2014. A review on circular economy: The expected transition to a balanced interplay of environmental and economic systems. J. Clean. Prod. https://doi.org/10.1016/j.jclepro.2015.09.007

Greiner, R., 2013. Social dimensions of market-based instruments: Introduction. Land use policy 31, 1-3. https://doi.org/10.1016/j.landusepol.2012.04.022

Gullì, L., Zazzi, M., 2011. Renewal strategies for the environmental conversion of crafts districts in Italy. Procedia Eng. 21, 771-779. https://doi.org/10.1016/j.proeng.2011.11.2077

Jacobsen, R., Buysse, J., Gellynck, X., 2013. Cost comparison between private and public collection of residual household waste: Multiple case studies in the Flemish region of Belgium. Waste Manag. 33, 3-11. https://doi.org/10.1016/j.wasman.2012.08.015

Kaza, S., Yao, L., Bhada-Tata, P., Van Woerden, F., 2018. What a Waste 2.0: A Global Snapshot of Solid Waste Management to 2050. The World Bank, Washington, DC. https://doi.org/10.1596/978-1-4648-1329-0

Kirchherr, J., Reike, D., Hekkert, M., 2017. Conceptualizing the circular economy: An analysis of 114 definitions. Resour. Conserv. Recycl. 127, 221-232. https://doi.org/10.1016/j.resconrec.2017.09.005

Lavee, D., Nardiya, S., 2013. A cost evaluation method for transferring municipalities to solid waste source-separated system. Waste Manag. 33, 1064-1072. https://doi.org/10.1016/J.WASMAN.2013.01.026

Liu, Y., Ge, Y., Xia, B., Cui, C., Jiang, X., Skitmore, M., 2019. Enhancing public acceptance towards waste-to-energy incineration projects: Lessons learned from a case study in China. Sustain. Cities Soc. 48, 101582. https://doi.org/10.1016/J.SCS.2019.101582

Loures, L., 2015. Post-industrial landscapes as drivers for urban redevelopment: Public versus expert perspectives towards the benefits and barriers of the reuse of post-industrial sites in urban areas. Habitat Int. 45, 72-81. https://doi.org/10.1016/j.habitatint.2014.06.028 
Makarichi, L., Jutidamrongphan, W., Techato, K., 2018. The evolution of waste-to-energy incineration: A review. Renew. Sustain. Energy Rev. 91, 812-821. https://doi.org/10.1016/J.RSER.2018.04.088

Malinauskaite, J., Jouhara, H., Czajczyńska, D., Stanchev, P., Katsou, E., Rostkowski, P., Thorne, R.J., Colón, J., Ponsá, S., Al-Mansour, F., Anguilano, L., Krzyżyńska, R., López, I.C., Vlasopoulos, A., Spencer, N., 2017. Municipal solid waste management and waste-to-energy in the context of a circular economy and energy recycling in Europe. Energy 141, 2013-2044. https://doi.org/10.1016/J.ENERGY.2017.11.128

Massarutto, A., 2015. Economic aspects of thermal treatment of solid waste in a sustainable WM system. Waste Manag. 37, 45-57. https://doi.org/10.1016/J.WASMAN.2014.08.024

Molinos-Senante, M., Hernández-Sancho, F., Sala-Garrido, R., 2010. Economic feasibility study for wastewater treatment: A cost-benefit analysis. Sci. Total Environ. 408, 4396-4402. https://doi.org/10.1016/j.scitotenv.2010.07.014

Rajendran, K., Sudharsan, V. V, Mahapatra, D.M., Kondusamy, D., 2018. Economics of Solid Waste Management, in: R, S., R, A., R, K., R, Sukumaran (Eds.), Waste to Wealth. Energy, Environment, and Sustainability. Springer, Singapore, pp. 259-275. https://doi.org/10.1007/978-981-10-7431-8_12

Roumboutsos, A., Kapros, S., Vanelslander, T., 2014. Green city logistics: Systems of Innovation to assess the potential of E-vehicles. Res. Transp. Bus. Manag. 11, 43-52. https://doi.org/10.1016/j.rtbm.2014.06.005

Scharff, H., 2014. Landfill reduction experience in The Netherlands. Waste Manag. 34, 2218-2224. https://doi.org/10.1016/J.WASMAN.2014.05.019

Schreck, M., Wagner, J., 2017. Incentivizing secondary raw material markets for sustainable waste management. Waste Manag. 67, 354-359. https://doi.org/10.1016/J.WASMAN.2017.05.036

Swart, J., Groot, L., 2015. Waste management alternatives: (Dis)economies of scale in recovery and decoupling. Resour. Conserv. Recycl. 94, 43-55. https://doi.org/10.1016/J.RESCONREC.2014.11.005

Tisserant, A., Pauliuk, S., Merciai, S., Schmidt, J., Fry, J., Wood, R., Tukker, A., 2017. Solid Waste and the Circular Economy: A Global Analysis of Waste Treatment and Waste Footprints. J. Ind. Ecol. 21, 628-640. https://doi.org/10.1111/jiec.12562

Tomić, T., Schneider, D.R., 2020. Circular economy in waste management - Socio-economic effect of changes in waste management system structure. J. Environ. Manage. 267, 110564. 
https://doi.org/https://doi.org/10.1016/j.jenvman.2020.110564

Trulli, E., Ferronato, N., Torretta, V., Piscitelli, M., Masi, S., Mancini, I., 2018. Sustainable mechanical biological treatment of solid waste in urbanized areas with low recycling rates. Waste Manag. 71, 556-564. https://doi.org/10.1016/J.WASMAN.2017.10.018

Wooldridge, J.M., 2020. Introductory econometrics, 7th ed. Cengage, Boston.

Yao, L., Van Woerden, F., 2018. Financing and Cost Recovery for Waste Management Systems, in: Kaza, S., Yao, L.C.., Bhada-Tata, P., Van Woerden, F. (Eds.), What a Waste 2.0: A Global Snapshot of Solid Waste Management to 2050. World Bank, pp. 101-114. https://doi.org/10.1596/978-1-4648-1329-0_ch5

Zaman, A.U., 2016. A comprehensive study of the environmental and economic benefits of resource recovery from global waste management systems. J. Clean. Prod. 124, 41-50. https://doi.org/10.1016/J.JCLEPRO.2016.02.086

Zeller, V., Towa, E., Degrez, M., Achten, WMJ, 2019. Urban waste flows and their potential for a circular economy model at city-region level. Waste Manag. 83, 83-94. https://doi.org/10.1016/J.WASMAN.2018.10.034 


\section{Appendices}

Table A1 contains information that is supplementary to the main body of the paper with reference to waste management facilities across Italy. Table A1 contains additional information regarding the breakdown of waste treatment to gain a view on how such facilities are spread across the country. Figure A1 helps to better understand the destination of the waste treated in MBT facilities in light of the importance of their role within the Italian waste management system. Table A2 shows key statistics of variables used in the econometric model presented in Table 4 while Table A3 contains Table 4 results in details.

Table A1 shows a breakdown of waste management facilities by region and typology. For example, what emerges clearly from Table A1 is that densely populated regions, such as Sicily and Lazio, do not have enough $\mathrm{WtE}$ capacity.

Table A1. Waste management facilities across Italy by region and type

\begin{tabular}{|c|c|c|c|c|c|}
\hline Region & Composting & Anaerobic dig. & $\mathrm{MBT}$ & Landfill & $\mathrm{WtE}$ \\
\hline Piedmont & 18 & 6 & 11 & 13 & 2 \\
\hline Aosta Valley & 2 & 0 & 0 & 2 & 0 \\
\hline Lombardy & 64 & 14 & 8 & 8 & 18 \\
\hline Trentino-A A & 11 & 6 & 1 & 6 & 1 \\
\hline Veneto & 44 & 10 & 6 & 12 & 3 \\
\hline Friuli-V G & 13 & 2 & 3 & 1 & 1 \\
\hline Liguria & 8 & 1 & 5 & 5 & 0 \\
\hline Emilia-R & 13 & 8 & 9 & 9 & 9 \\
\hline Tuscany & 16 & 0 & 15 & 7 & 6 \\
\hline Umbria & 4 & 4 & 5 & 4 & 0 \\
\hline Marche & 6 & 0 & 6 & 9 & 0 \\
\hline Lazio & 20 & 0 & 11 & 5 & 1 \\
\hline Abruzzo & 6 & 0 & 5 & 6 & 0 \\
\hline Molise & 2 & 1 & 3 & 3 & 1 \\
\hline Campania & 4 & 2 & 7 & 2 & 1 \\
\hline Apulia & 9 & 1 & 11 & 9 & 2 \\
\hline Basilicata & 0 & 0 & 1 & 5 & 2 \\
\hline Calabria & 6 & 1 & 9 & 4 & 1 \\
\hline Sicily & 19 & 1 & 9 & 11 & 0 \\
\hline Sardinia & 16 & 1 & 6 & 6 & 1 \\
\hline Italy & 281 & 58 & 131 & 127 & 49 \\
\hline
\end{tabular}

Source: own elaboration based on data published by ISPRA. Note: "WtE" includes co-incinerators.

“Anaerobic digestion" includes integrated treatment. 
Figure A1 shows destination of the waste treated in MBT facilities. It seems quite clear that the role of MBT facilities is not constantly instrumental in achieving circular economy goals.

Figure A1. Output of MBT facilities according to waste destination.

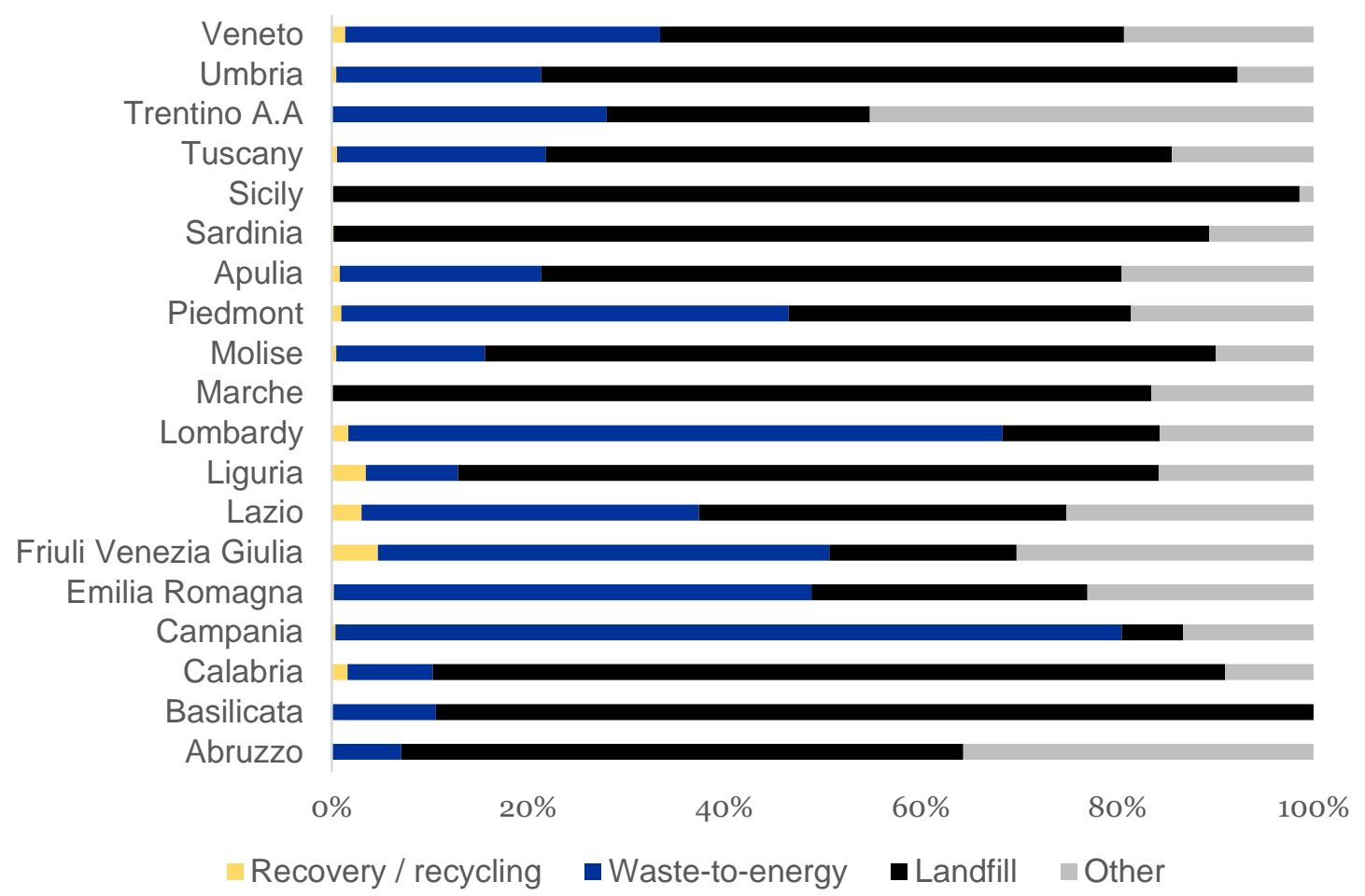

Source: Own elaboration. Note: "Other" includes further treatment, sewage treatment plant, storage of materials, and landfill-covering soil.

Table A2 and Table A3 present key statistical information regarding the variables used in our analyses. First, Table A2 gives the mean, standard deviation, minimum, and maximum of the variables used in the econometric model (see Table 4) in order better contextualize the variables within the Italian case.

Table A2. Regressors key statistics

\begin{tabular}{lccccc}
\hline Variable & Obs. & Mean & Std. Dev. & Min & Max \\
\hline alt & 4,702 & 5.089 & 1.321 & 0 & 7.504 \\
cec & 4,723 & 267.384 & 101.339 & 103.355 & 477.112 \\
den & 4,703 & 5.249 & 1.255 & 1.764 & 9.380 \\
lan & 4,723 & 21.499 & 20.211 & 3.602 & 92.531 \\
mbt & 4,723 & 29.349 & 20.554 & 0 & 83.422 \\
org & 4,723 & 27.885 & 15.803 & 0 & 64.17618 \\
sea & 4,703 & 0.083 & 0.2761 & 0 & 1 \\
sor & 4,723 & 62.411 & 18.326 & 10.036 & 89.935 \\
was & 4,723 & 447.546 & 126.476 & 199.771 & 1041.407 \\
wmc & 4,723 & 316.593 & 99.390 & 124.210 & 601.1 \\
wte & 4,723 & 20.481 & 14.596 & 0 & 69.324 \\
\hline
\end{tabular}


Table A3 presents crucial information concerning the econometric outputs summarized in Table 4. In the top section, the output of the main econometric model with the dependent variable is the waste management cost. Similarly, the middle and bottom sections present the output for the two special cases that take account of treatment and disposal costs and recovery costs, respectively.

\begin{tabular}{|c|c|c|c|c|c|c|}
\hline wmc & Coef. & Std. Err. & $\mathrm{t}$ & $\mathrm{P}>\mathrm{t}$ & [95\% Conf. & Interval] \\
\hline \multicolumn{7}{|c|}{ Table 4 (1) } \\
\hline alt & -4.902 & 1.057 & -4.640 & 0.000 & -6.974 & -2.830 \\
\hline den & -11.735 & 1.007 & -11.650 & 0.000 & -13.709 & -9.761 \\
\hline sea & 41.820 & 4.895 & 8.540 & 0.000 & 32.224 & 51.417 \\
\hline sor & 0.236 & 0.077 & 3.060 & 0.002 & 0.085 & 0.388 \\
\hline was & -0.114 & 0.010 & -11.000 & 0.000 & -0.134 & -0.094 \\
\hline $\mathrm{mbt}$ & 1.215 & 0.096 & 12.670 & 0.000 & 1.027 & 1.403 \\
\hline lan & -0.664 & 0.082 & -8.060 & 0.000 & -0.826 & -0.503 \\
\hline wte & -0.436 & 0.097 & -4.480 & 0.000 & -0.626 & -0.245 \\
\hline org & -1.631 & 0.089 & -18.270 & 0.000 & -1.806 & -1.456 \\
\hline cec & -0.215 & 0.016 & -13.010 & 0.000 & -0.247 & -0.182 \\
\hline _cons & 526.295 & 13.740 & 38.310 & 0.000 & 499.359 & 553.231 \\
\hline \multicolumn{7}{|c|}{ Table 4 (2) } \\
\hline alt & -3.355 & 0.867 & -3.870 & 0.000 & -5.055 & -1.654 \\
\hline den & -9.339 & 0.867 & -10.770 & 0.000 & -11.039 & -7.639 \\
\hline sea & 11.321 & 4.203 & 2.690 & 0.007 & 3.081 & 19.562 \\
\hline sor & 0.776 & 0.066 & 11.800 & 0.000 & 0.647 & 0.904 \\
\hline was & -0.032 & 0.009 & -3.560 & 0.000 & -0.049 & -0.014 \\
\hline $\mathrm{mbt}$ & 0.582 & 0.080 & 7.240 & 0.000 & 0.424 & 0.739 \\
\hline lan & -0.550 & 0.071 & -7.720 & 0.000 & -0.690 & -0.410 \\
\hline wte & -0.193 & 0.085 & -2.260 & 0.024 & -0.359 & -0.026 \\
\hline cec & -0.082 & 0.014 & -5.830 & 0.000 & -0.109 & -0.054 \\
\hline _cons & 201.585 & 11.468 & 17.580 & 0.000 & 179.102 & 224.069 \\
\hline \multicolumn{7}{|c|}{ Table 4 (3) } \\
\hline alt & -1.258 & 1.402 & -0.900 & 0.370 & -4.008 & 1.491 \\
\hline den & -0.503 & 1.296 & -0.390 & 0.698 & -3.044 & 2.037 \\
\hline sea & -4.613 & 6.805 & -0.680 & 0.498 & -17.954 & 8.729 \\
\hline sor & -0.512 & 0.108 & -4.720 & 0.000 & -0.725 & -0.299 \\
\hline was & -0.050 & 0.014 & -3.550 & 0.000 & -0.078 & -0.023 \\
\hline $\mathrm{mbt}$ & 0.427 & 0.124 & 3.430 & 0.001 & 0.183 & 0.671 \\
\hline org & -0.351 & 0.122 & -2.880 & 0.004 & -0.590 & -0.112 \\
\hline cec & -0.033 & 0.022 & -1.490 & 0.135 & -0.077 & 0.010 \\
\hline _cons & 126.015 & 19.183 & 6.570 & 0.000 & 88.406 & 163.624 \\
\hline
\end{tabular}

Table A3. Additional information based on the output of Table 4. Source: Own elaboration. 